\title{
WORLD STUDENT CHRISTIAN FEDERATION (WSCF) \\ FEDERATION UNIVERSELLE DES ASSOCIATIONS CHRETIENNES D'ETUDIANTS (FUACE)
}

5 route des Morillons

1218 Grand-Saconnex (GE) (Switzerland)

1895

Tel: (22) 7988953

Fax: (22) 7982370

Telex: 415730 oik ch

Cables: fuace

Chairman: Marshall Fernando

Co-Secretaries-General: Jean-François

Delteil; Clarissa Balan-Sycip

An international non-governmental organization which provides a meeting place for students, crossing boundaries of culture, race and religion. National movements linked to WSCF are found in approximately ninety countries and are diverse in character. Some are nationalecumenical student movements, usually called Student Christian Movement. Others are denominational youth or student organizations. Some are composed mainly of students. Others have the active participation of teachers, pastors and workers. Some are based in universities, colleges and schools. Others are small groups of committed people. Activities include Bible study, worship, political involvement based on Christian commitment, research and documentation, solidarity actions. Structurally, the national movements cluster around WSCF Regional Offices which administer most of the international programmes. The Inter-Regional Office in Geneva serves an overall coordinating function.

Principal publications include: WSCF Journal; Federation New's; occasional dossiers and books and regional publications.

La Fédération universelle des associations chrétiennes d'étudiants (FUACE) est une organisation internationale nongouvernementale qui offre un lieu de réunion aux étudiants, sans distinction de culture, de race ou de religion. Des mouvements nationaux associés à la Fédération, ayant chacun leur caractère propre, existent dans quelque quatre-vingt dix pays. Les uns sont des mouvements oecuméniques nationaux d'étudiants, généralement sous l' appellation de Mouvement chrétien des étudiants, d'autres sous la dénomination d'organisations de jeunesse ou d'étudiants. Les autres sont constitués principalement d'étudiants. D'autres encore reçoivent une participation active des professeurs, pasteurs et travailleurs. Les uns ont leur siège dans les universités, collèges et écoles. Les autres constituent de petits groupes de personnes engagées. Les activités comprennent: les études bibliques, le culte, les engagements politiques basés sur l'enseignement chrétien, la recherche et la documentation, les actions de solidarité. Structurellement, les mouvements nationaux se regroupent autour des bureaux régionaux de la FUACE, qui gèrent la plupart des programmes internationaux. Le Bureau inter-régionalde Genève joue le rôle de coordinateur général.

Parmi les publications principales: "WSCF Journal"; "Federation Nen's"; plus des dossiers occasionnels, des livres, et des publications régionales. 